\title{
A NEGOCIAÇ̃̃O COLETIVA E SEU ALCANCE NO ORDENAMENTO JURÍDICO BRASILEIRO
}

Luciana Aboim Machado Gonçalves da Silva

Professora Adjunta da Universidade Federal de Sergipe - UFS. Doutora em Direito do Trabalho pela Faculdade de Direito da Universidade de São Paulo-USP. Mestre em Direito do Trabalho, especialista em Direito do Trabalho e em Direito Processual Civil, todos pela Pontifícia Universidade Católica de São Paulo (PUC/ SP). Vice-Presidente da Asociación Iberoamericana de Derecho de Trabajo y de la Seguridad Social.

Lucas Gonçalves da Silva

Professor Adjunto da Universidade Federal de Sergipe - UFS. Doutor em Direito Constitucional pela Pontifícia Universidade Católica de São Paulo - PUC/SP. Coordenador do Mestrado em Direito da UFS.

\section{Resumo}

O sistema de juridificação trabalhista pautado na valorização da negociação coletiva tem sido preconizado no direito pátrio e estrangeiro, uma vez que traduzem diretamente interesses das categorias econômicas e profissionais, ao lado de possibilitar o acesso a peculiaridades da vivência do labor que não cabem ser disciplinadas na dimensão geral e abstrata da lei.

\section{Palavras-chave}

Normas autônomas coletivas; Sindicatos; Crise econômica; Adaptação.

\section{Abstract}

The system of ruled labor based in the valorization collective negotiation has been foreseen in the right national and foreigner, once they translate interests of the economical and professional categories directly, beside making possible the access to specificities of the existence of the labor that cannot be disciplined in the general and abstract dimension of the law.

\section{Key word}

Collective autonomous norms; Unions; Economical crisis; Adaptation. 


\section{Introdução}

$\mathrm{Na}$ evolução das relaçóes entre capital e trabalho evidencia-se o grande relevo das normas coletivas na pacificação social de conflitos e conquista de direitos laborais, que, sendo manifestaçôes de negociaçôes legítimas, os reais interesses coletivos das categorias econômicas e profissionais.

A convenção ou acordo coletivo de trabalho, nascida da negociação coletiva vitoriosa, compóe-se fundamentalmente de normas jurídicas que delineiam condiçóes de labor aplicáveis, no lapso de vigência, às relaçôes individuais de trabalho abarcadas no âmbito pessoal e espacial de representação dos entes convenentes.

Dessarte, por formarmos um Estado Democrático de Direito, a Constituição Federal de 1998 imprimiu nova roupagem à autonomia privada coletiva, privilegiando este poder social de solucionar conflitos laborais, pois ninguém melhor do que os próprios atores sociais, que vivenciam o cotidiano laboral, para saber das possibilidades de avanço e retrocesso na construção do Direito.

Relevante faz-se salientar, contudo, esse poder dos interlocutores sociais na formação do Direito não é absoluto e ilimitado, sujeitando-se a limites imprescindíveis para harmonia do ordenamento jurídico.

É corrente o estabelecimento de normas coletivas do trabalho que estabelecem os banco de horas com jornadas $12 \times 36$ ou 24x72, mormente aplicadas a categorias de vigilantes ou profissionais de saúde. Tais normas são válidas tendo em vista disciplinar tema relacionado a saúde do trabalhador? Qual o alcance das normas coletivas considerando que a Constituição Brasileira valorizou a negociação coletiva?

Nesse diapasão, no presente artigo, cabe analisar o pluralismo normativo do Direito Laboral, salientando os modelos normativos existentes e o adotado pelo sistema jurídico brasileiro.

\section{A Negociação Coletiva: Seu Sentido e Relevo}

Ao se tratar de negociação coletiva, impende destacar, a princípio, a sua acepção que consiste no método de autocomposição de interesses coletivos pertinente a representantes de trabalhadores e empregadores ${ }^{1}$, visando a encontrar fórmulas para a solução de conflitos coletivos e, por conseguinte, disciplinar as relaçóes de trabalho.

1 Consoante nosso ordenamento jurídico laboral, é representante legal dos trabalhadores o sindicato profissional e dos empregadores, o sindicato patronal (convençáo coletiva de trabalho) ou a própria empresa (acordo coletivo de trabalho). Impende frisar, a obrigatoriedade de participação dos sindicatos na negociação coletiva (CF, art. $8 .^{\circ}$, inciso VI) refere-se aos trabalhadores, pois, do lado empresarial, a intervençấo do sindicato nấo se mostra indispensável à garantia da igualdade das partes na negociação coletiva. 
No dizer de TEIXEIRA FILHO (SÜSSEKIND, 2002, p. 1.131.):

A negociação coletiva de trabalho pode ser singelamente definida como o processo democrático de autocomposição de interesses pelos próprios atores sociais, objetivando a fixação de condiçōes de trabalho aplicáveis a uma coletividade de empregados de determinada empresa ou de toda uma categoria econômica e a regulamentação entre as entidades estipulantes.

BAYLOS (1997, p.78-79) conceitua:

Trasladada a la rama de producción, la negociación colectiva es un instrumento de gobierno del sistema de relaciones laborales, contemplado en la empresa un articulado sistema de límites y un conjunto de procedimientos, con frecuencia no formalizados, que procuran la producción de consenso en la administración de las relaciones laborales y la racionalización del ejercicio de la autoridad en la empresa. ${ }^{2}$

Amplo é o conceito provindo da Organização Internacional do Trabalho (RUPRECHT, 1995, p. 264-265.):

Entende-se por negociação coletiva (ou expressões equivalentes) não só as discussóes que culminam num contrato (convenção ou acordo) coletivo conforme o define e regulamenta a lei, mas, além disso, todas as formas de tratamento entre empregadores e trabalhadores, ou entre seus respectivos representantes, sempre e quando suponham uma negociação no sentido corrente da palavra.

A negociação coletiva, como ensina JEAMMAUD (1997, p. 245.), constitui-se no meio de fixação de novos equilíbrios entre aspiraçóes amplamente antagônicas, de arte a reforçar o crédito das organizaçóes, bem como assegurar a legitimidade de eventual lege ferenda.

Vale consignar, a Organização Internacional do Trabalho - OIT - tem assumido uma posição de incentivo à negociação coletiva, considerando-a como melhor forma de composição dos interesses coletivos nas relaçôes de labor.

Nessa perspectiva, a Convenção n. ${ }^{\circ} 98$ da OIT, ratificada pelo Brasil (Decreto n. ${ }^{\circ}$ 33.196, de 22.6.53), no art. $4 .^{\circ}$, dispóe que

deverão adotar-se medidas adequadas às condiçôes nacionais quando isso seja necessário para estimular e fomentar entre os empregadores e as organizaçōes de empregadores, por um lado, e as organizaçōes de trabalhadores, por outro,

2 Trasladado ao ramo de produção, a negociação coletiva é um instrumento de governo do sistema de relaçóes laborais, contemplando na empresa um articulado sistema de limites e um conjunto de procedimentos, com freqüência não formalizados, que procuram a produção de consenso na administração das relaçóes laborais e a racionalização do exercício da autoridade na empresa. (tradução nossa) 
o pleno desenvolvimento e uso de procedimentos de negociaçáo voluntária, com o objetivo de regulamentar, por meio dos contratos coletivos, as condições de emprego. (Oficina Internacional del Trabajo, 1994, p. 199.)

Já a Convenção n. ${ }^{\circ} 154$ da OIT, ratificada pelo Brasil (Decreto n. ${ }^{\circ}$ 1256, de 29.9.94), conhecida por fomentar à negociação coletiva, no seu art. 5.1 determina: Deverão ser adotadas medidas adequadas às condiçóes nacionais para fomentar a negociação coletiva. O parágrafo $2 .^{\circ}$ desse mesmo artigo enumera as medidas adequadas para tal fim; são elas: a) que a negociação coletiva seja possibilitada a todos os empregadores e a todas as categorias de trabalhadores de todos os ramos da atividade econômica; b) que a negociação coletiva seja progressivamente estendida a todas as matérias a que se refere o art. $2 .^{\circ}$ da Convenção, que são fixar as condiçốes de trabalho e emprego, regular as relaçóes entre empregadores e trabalhadores e as relaçóes entre empregadores ou suas organizaçóes e uma ou várias organizaçôes de trabalhadores; c) fomentar o estabelecimento de regras de procedimento avençadas entre as organizaçôes dos empregadores e as organizaçóes dos trabalhadores; d) que a negociação coletiva não resulte impedimento pela inexistência de regras que determinem o seu desenvolvimento ou a insuficiência ou o caráter impróprio de tais regras; e e) que os órgãos e procedimentos de solução de conflitos laborais estejam concebidos de tal maneira que contribuam ao fomento da negociação coletiva. (Oficina Internacional del Trabajo, 1994, p. 235)

Nesse diapasão, os atores sociais devem efetivamente promover a negociação coletiva, de maneira a náo ser rechaçada ao primeiro aceno. É certo que o processo de entendimento náo tem de necessariamente desaguar em convenção ou acordo coletivo de trabalho, mas esse é o ideal a ser perseguido, não podendo ser rejeitada a tentativa de ajuste de interesses coletivos. No Brasil, o dever de negociar se depreende do artigo 616, caput, da CLT ${ }^{3}$.

$\mathrm{Na}$ esteira de valorização da negociação coletiva, a Emenda Constitucional 45 alterou, em 2004, a redação do art. 114, dispondo no $\$ 2^{\circ}$ "in verbis":

Recusando-se qualquer das partes à negociaçâo coletiva ou à arbitragem, é facultado às mesmas, de comum acordo, ajuizar dissidio coletivo de natureza econômica, podendo a Justiça do Trabalho decidir o conflito, respeitadas as disposiçôes minimas legais de proteção ao trabalho, bem como as convencionadas anteriormente. (grifo nosso)

De igual modo, partindo da perspectiva de prestigiar as fontes de direito autônomas, a súmula 277 do Tribunal Superior do Trabalho adotou a teoria da ultratividade estabelecendo:

3 Art. 616, caput, da CLT: Os Sindicatos representativos de categorias econômicas ou profissionais e as empresas, inclusive as que não tenham representação sindical, quando provocados, não podem recusar-se à negociaçâo coletiva. 
"As cláusulas normativas dos acordos coletivos ou convenções coletivas integram os contratos individuais de trabalho e somente poderão ser modificadas ou suprimidas mediante negociação coletiva de trabalho."

\section{Alcance da Negociação Coletiva no Ordenamento Jurídico Brasileiro}

É preciso ter em mira que as normas autônomas juscoletivas, oriundas do processo frutífero de negociação coletiva, devem se coadunar com o padrão geral heterônomo justrabalhista e que, portanto, ao serem entabuladas mister faz-se a observância de certas disposiçóes constitucionais ou legais.

A propósito, o constitucionalista SILVA (1998, p. 73-74) realça que rege o nosso sistema jurídico o princípio da coerência e harmonia das normas, lecionando:

as normas juridicas vinculam-se entre si por um fundamento único, de tal modo que, para configurarem um sistema harmônico, as normas legais devem harmonizar-se, seguindo uma escala de importância, de tal maneira que as normas inferiores devem submeter-se aos mandamentos das normas superiores, sob pena de, não o fazendo, tornarem-se inválidas. Há, portanto, entre as várias fontes, uma hierarquia, que garante a coerência do sistema jurídico.

O jurista MANUS (2011, p.119), com percuciência, explana que o Direito do Trabalho, de igual modo aos demais ramos do Direito, obedece à hierarquia das fontes ${ }^{4}$, de maneira que as normas hierarquicamente inferiores só podem dispor, sobre o mesmo tema, de forma diversa em relação ao que determina a norma hierarquicamente superior quando esta permitir tratamento diverso, pois caso contrário haverá conflito entre as normas, prevalecendo a hierarquicamente superior.

Assim sendo, merece reparo a assertiva de alguns juslaboralistas na direção de que o Direito do Trabalho não obedece, do mesmo modo que os demais ramos do Direito, à hierarquia das fontes ${ }^{5}$, uma vez que as normas inferiores estão adstritas ao estatuído por normas hierarquicamente superiores.

O Estatuto Supremo de 1988 possibilitou que outras fontes de Direito estabeleçam condiçóes de maneira mais favorável ao obreiro em relação ao conteúdo normativo constitucional, quando no art. 7. ${ }^{\circ}$, caput, insculpe serem direitos dos trabalhadores aqueles

4 A explicitar, ressaltam-se, em ordem hierárquica, as fontes formais do Direito do Trabalho: a Constituiçáo Federal, a lei complementar, a lei ordinária, a lei delegada, a medida provisória, regulamentos normativos, a sentença normativa da Justiça do Trabalho, a convenção coletiva de trabalho, o acordo coletivo de trabalho, o regulamento de empresa, o contrato individual de trabalho e os usos e costumes.

5 Entendem ser peculiaridade do Direito Laboral a aplicação do princípio da norma mais favorável na hierarquia das fontes, de modo que o vértice da pirâmide da hierarquia das normas trabalhistas será ocupado pela norma mais favorável ao trabalhador. 
pela mesma enumerados além de outros que visem à melhoria de sua condição social e no art. $114, \$ 2 .^{\circ}$, determina que a sentença normativa substitutiva da negociação direta deve respeitar os direitos mínimos legais e convencionais assegurados aos trabalhadores. ${ }^{6}$

É esteio do Direito Laboral, por conseguinte, o princípio protetor do obreiro, orientando no sentido de que as normas de maior hierarquia são postergadas por outras de menor (por exemplo, respectivamente, a lei e a convenção coletiva) quando estas últimas estabelecem melhores benefícios a favor dos trabalhadores.

Em que pese o sistema normativo laboral autorizar que a vontade privada, individual ou coletiva, ajuste condiçóes mais favoráveis ao trabalhador em comparação às consubstanciadas pelo texto constitucional ou legal, pode haver normas legais de natureza proibitivas que impóem limites à autonomia dos particulares, com miras ao interesse geral, fundadas na ordem pública econômica, impedindo disposição convencional sobre determinado assunto. Isso se deve ao fato de que é preciso compatibilizar a autonomia privada com a responsabilidade estatal de guiar as políticas que conduzam ao logro de seus objetivos em função do bem comum.

Uma prática adotada em momentos de crise, que autoriza excepcionalmente a revisitação na aplicação do princípio da norma mais favorável, consiste na permissão de que fontes do Direito de nível hierárquico inferior disciplinem in pejus certas condiçóes de labor, apoiadas em uma negociaçáo coletiva com base em concessóes recíprocas em que a perda de certo direito tem por fulcro a obtenção de um outro, reputado de valor superior (à guisa de ilustração frisamos emprego versus diminuição de salário e jornada). Parte expressiva de doutrinadores pátrios e estrangeiros reconhece nisso uma versão atualizada do princípio protetório.

Nessa órbita, a normativa constitucional (CF, art. 7. ${ }^{\circ}$, incisos VI, XIII e XIV) prescreveu a possibilidade de norma autônoma coletiva in pejus ao obreiro através da convenção ou acordo coletivo de trabalho. Registra-se, essa flexibilização das condiçóes de trabalho tem por escopo diminuir custos e preservar o emprego nos períodos de crise empresarial. $^{7}$

A elucidar, são os escólios de ROBORTELLA (1994, p. 97):

\section{(...) definimos a flexibilização do direito do trabalho como o instrumen- to de politica social caracterizado pela adaptação constante das normas}

6 Nessa mesma diretriz, de aplicação do princípio da norma mais favorável, dispõe o art. 620 da CLT que as condiçóes estabelecidas em Convençāo, quando mais favoráveis, prevalecerão sobre as estipuladas em Acordo.

7 Não se pode confundir a flexibilizaçấo laboral com a desregulamentaçấo do Direito do Trabalho que retira a proteçāo do Estado ao trabalhador, permitindo que a autonomia privada, individual ou coletiva regule as condiçôes de trabalho e os direitos e obrigaçôes advindos da relaçâo de emprego (SÜSSEKIND, 2002, p. 142). 
juridicas à realidade econômica, social e institucional, mediante intensa participação de trabalhadores e empresários, para eficaz regulação do mercado de trabalho, tendo como objetivos o desenvolvimento econômico e o progresso social.

Agrega-se a isso a advertência do juslaboralista URIARTE (1994, p. 1.045-1.050) de que a admissibilidade da negociação coletiva in pejus em relação ao estabelecido por lei depende, em princípio, da natureza originária ou derivada que se atribua à autonomia coletiva. Se a gênese da autonomia é originária, o ordenamento heterônomo não pode limitá-la. No entanto, se a considera derivada, a procedência da negociação dependerá de que as normas heterônomas sejam imperativas ou não, de direito absoluto necessário, derivado ou disponível, o que pressupóe a supremacia do ordenamento estatal e o caráter derivado do autônomo.

Nesse diapasão, há dois parâmetros a serem considerados dentro de um modelo trabalhista democrático: "normatização autônoma e privatística" e "normatização privatística subordinada". No primeiro, vigorante no modelo anglo-saxão, há plena liberdade entre particulares (ou seja, ampla margem de criatividade) e no segundo existe um limite no patamar mínimo de direitos estabelecidos pela normatização estatal. ( DELGADO, 2002, p. 1369-1373)

Em observância à situação de que a lei e a autonomia privada coletiva têm fundamento nas disposiçóes normativas constitucionais, dúvidas não pairam das suas naturezas derivadas e da necessidade de se coadunarem às disposiçóes de normas hierarquicamente superiores. Ou seja, o sistema brasileiro enquadra-se no modelo de "normatização privatística subordinada”.

Na esteira dessas idéias, SIMON (1998, p. 473-474) ensina:

Se han definido como relaciones básicas entre la heteronomía y la autonomía, las siguientes:

1) Relación de suplementariedad: por la que el Estado fija un tratamiento minimo, inderogable 'in pejus' por el convenio colectivo;

2) Relación de complementariedad: donde el Estado se limita a establecer las bases o principios de la regulación y remite o reenvía a la negociación colectiva su concreción y su desarrollo;

3) Relación de supletoriedad: la norma estatal proporciona una regulación del supuesto, que sólo se aplicará caso no existir una previsión diferente en cualquier sentido por parte del convenio colectivo;

4) Relación de exclusión de la negociación colectiva: el Estado se reserva para si la regulación de una determinada materia o de aspectos de la misma, y la norma estatal es intangible e inmodificable para el convenio colectivo; 
5) Relación norma estatal y convencional: planteada cuando la primera es insuperable 'in melius' por la segunda. ${ }^{8}$

Também é nesse mesmo contexto que o professor MANUS (2011, p.119), adotando as lições de José Barros de Moura, classifica as normas jurídicas trabalhistas em:

- normas facultativas (dispositivas ou supletivas): que admitem qualquer regulamentação diferente, num sentido mais favorável ou menos favorável ao trabalhador;

- normas imperativas absolutas: que não admitem qualquer modificação em sentido diferente, seja ele mais ou menos favorável ao trabalhador;

- normas imperativas máximas: que não admitem qualquer modificação em sentido favorável ao trabalhador;

- normas imperativas minimas: que não admitem qualquer modificação em sentido menos favorável ao trabalhador, mas permitem todas as modificaçóes num sentido mais favorável.

Dessarte, há limites jurídicos objetivos de validade e eficácia jurídica das normas autônomas coletivas, quais sejam:

a) admite-se norma juscoletiva in pejus quando haja expresso permissivo no ordenamento jurídico heterônomo (por exemplo, redução salarial - art. $7 .^{\circ}$, inciso VI, da CF/88) e desde que seja resultado de uma transação (despojamento multilateral com reciprocidade entre os entes envolvidos);

b) a norma coletiva não pode dispor sobre direitos amparados por normas de indisponibilidade absoluta, ou seja, normas embasadas em direitos humanos dos trabalhadores (a ilustrar, irredutibilidade do salário mínimo - art. 7.º, inciso IV, da CF); e

c) a norma autônoma coletiva pode regular de modo mais favorável em comparação às normas de indisponibilidade relativa, também denominadas de normas

8 Definiram-se como relaçóes básicas entre a heteronomia e a autonomia, as seguintes:

1) Relação de suplementaridade: pela qual Estado fixa um tratamento minimo, inderrogável 'in pejus' pelo convênio coletivo;

2) Relação de complementaridade: onde o Estado se limita a estabelecer as bases ou princípios da regulamentaçâo e remete ou reenvia à negociação coletiva sua concreção e seu desenvolvimento;

3) Relação de supletariedade: a norma estatal proporciona uma regulamentação da hipótese, que somente se aplicará caso náo exista uma previsão diferente em qualquer sentido por parte do convênio coletivo;

4) Relação de exclusão da negociação coletiva: o Estado reserva para si a regulação de uma determinada matéria ou de aspectos da mesma, e a norma estatal é intangivel e imodificável para o convênio coletivo;

5) Relaçâo norma estatal e convencional: estabelecida quando a primeira é insuperável 'in melius' pela segunda. (tradução nossa) 
imperativas mínimas (a elucidar, art. 7. ${ }^{\circ}$ inciso XVI, da CF combinado com o art. $59, \$ 1 .^{\circ}$, da CLT, que explicitam a possibilidade de celebração de acordo de compensação de horas extraordinárias de trabalho limitada a jornada máxima de 10 horas diárias).

Assim, o pluralismo normativo laboral reconhece as normas coletivas são produzidas em um contexto de autocomposição de conflitos coletivos de trabalho, abrangendo a transação (em que há concessões recíprocas entre as partes envolvidas) e não renuncia ou submissão, de modo que deve respeitar um standard mínimo de direitos voltados a garantir e efetivar a dignidade do trabalhador.

Em havendo conflitos de normas coletivas e estatais que disciplinam a mesma matéria, cabe aplicar o "princípio da adequação setorial negociada" segundo o qual, nas liçóes de DELGADO (2002, p. 850.) as normas autônomas juscoletivas construídas para incidirem sobre uma certa comunidade econômico-profissional podem prevalecer sobre o padrão geral heterônomo justrabalhista desde que respeitados dois critérios autorizativos: a) quando as normas autônomas juscoletivas implementam um padrão setorial de direitos superior a norma estatal; b) quando as normas autônomas juscoletivas transacionam setorialmente parcelas justrabalhistas de indisponibilidade apenas relativa (e não de indisponibilidade absoluta).

Vale lembrar que as normas de indisponibilidade absoluta são aquelas que estão atreladas ao "patamar civilizatório mínimo", ou seja, que asseguram a dignidade do trabalhador, como as normas concernentes à saúde e segurança no trabalho, bases salariais mínimas e dispositivos antidiscriminatórios.

Assim, quando violadas ensejam a anulação das normas juscoletivas, sendo corrente a jurisprudência uniformizada do TST neste sentido. Á guisa de exemplo, destaca-se que o inciso II da súmula 437 deste Colendo Tribunal prevê:

"é inválida cláusula de acordo ou convenção coletiva de trabalho con-
templando supressão ou reduçấo do intervalo intrajornada porque este
constitui medida de higiene, saúde e segurança do trabalho, garantido
por norma de ordem publica (art. 71 da CLT e art. 7o, XXII, da CF/88)."

Nessa mira de estabelecer balizas à autonomia privada coletiva, com vista à preservaçáo de direitos humanos do trabalhador, foi cancelada a jurisprudência uniformizada expressa na súmula 349 do TST que estabelecia a validade do acordo coletivo ou convenção coletiva de compensação de jornada de trabalho em atividade insalubre, exigindo-se a inspeção prévia do meio ambiente do trabalho a cargo de médico ou engenheiro do trabalho do Ministério do Trabalho e Emprego.

Ainda nesse desiderato, convém gizar que existe divergência doutrinária e jurisprudencial na adoção do critério que determina a norma mais favorável quando do cotejo 
entre normas jurídicas que disciplinam de forma distinta uma mesma situação concreta. Os critérios de comparação esboçados na doutrina são: critério da acumulação ou fracionamento, critério do conglobamento e critério do conglobamento por instituiçôes.

A doutrina majoritária e a jurisprudência predominante do TST, fundamentando-se no disposto na Lei n. ${ }^{\circ} 7.064 / 82^{9}$, adota o critério global ou do conglobamento absoluto, que confronta os diplomas normativos de maneira integral (ou melhor, não fraciona os corpos jurídicos em preceitos ou institutos jurídicos), admitindo como válido aquele que, no conjunto, é mais favorável, ainda que este contenha algumas normas menos benéficas relativamente a preceitos de outro corpo normativo.

Outro caminho segue o critério da acumulação normativa, também denominado de atomista ou de fracionamento, que compara normas isoladas de distintos diplomas normativos, colidentes entre si no regulamento de um mesmo assunto, elegendo, nessa confrontação, a norma mais favorável e compondo uma espécie de novo corpo normativo que acumula todas as disposiçóes separadamente mais favoráveis.

Alguns doutrinadores fundamentam a aplicação desse critério no art. 620 da CLT, pois este se refere expressamente a condiçóes estabelecidas e não convenção mais favorável. Entrementes, esse pensar acaba por gerar uma colcha de retalhos de disposiçóes laborais, além de gerar dúvidas, entre empregadores e empregados, sobre os efetivos deveres e direitos respectivos.

A criticar essa corrente, DELGADO (2002, p. 1.371) testifica que tal teoria suprime o caráter universal e democrático do Direito, por tornar sempre singular a fórmula juridica aplicada a cada caso concreto.

É de se salientar que o TST, na súmula 261, adotou este critério da acumulação aplicando a disposição da Convenção 132 da OIT, embora, no conjunto da disciplina normativa das férias, a CLT seja mais benéfica - ao estabelecer: o empregado que se demite antes de completar 12 (doze) meses de serviço tem direito a férias proporcionais.

Para o terceiro critério, considerado como intermediário, chamado de conglobamento por instituiçôes ou critério de incindibilidade, deve ser eleito o conjunto normativo mais favorável relativo a um instituto de Direito do Trabalho. Tal critério é adotado expressamente na Argentina (Lei n. ${ }^{\circ} 14.250$, art. $6^{\circ}$ ), sendo qualificado por DEVEALI (1983, p. 328) como critério do conglobamiento orgánico ${ }^{10}$.

Em nossa opinião, o critério do conglobamento absoluto é de difícil aplicação, a par de ser subjetiva a aferição de que um regime é mais favorável globalmente que outro, e o

9 A Lei n. ${ }^{\circ} 7.064 / 82$ no art. 3.' , inciso III, dispóe sobre a aplicação da legislação brasileira de proteção ao trabalho, naquilo que não for incompativel com o disposto nesta Lei, quando mais favorável do que a legislaçâo territorial, no conjunto de normas e em relação a cada matéria.

10 Conglobamento orgânico. 
critério de acumulação leva à insegurança dos destinatários da norma, além de desqualificar o caráter geral das normas jurídicas.

Diante disso, a superar os entraves dos critérios anteriores, entendemos ser conveniente adotar o critério do conglobamento por instituiçóes, por ser um meio lógico e de mais fácil acepção, já que compara conjuntos suficientemente homogêneos de normas que disciplinam um instituto.

Em nosso pensar, a literalidade do art. 3. ${ }^{\circ}$, inciso III, da Lei n. ${ }^{\circ}$ 7.064/82 adota a teoria do conglobamento orgânico que dispóe a aplicação da legislação brasileira de proteção ao trabalho, naquilo que náo for incompativel com o disposto nesta Lei, quando mais favorável do que a legislação territorial, no conjunto de normas e em relação a cada matéria.

\section{Conclusões}

A negociação coletiva - processo dialético direcionado a engendrar normas autônomas coletivas - vem alcançando, mormente nos últimos tempos, um relevo particular, o que se infere através de uma interpretação sistemática do texto constitucional de 1988.

Entrementes, a despeito de ser instrumento de grande valia na harmonização das relações entre capital e trabalho, a negociação coletiva está sujeita a balizas impostas pelo sistema jurídico brasileiro, com vistas aos direitos humanos dos trabalhadores.

O Estatuto Supremo de 1988 possibilitou que outras fontes de Direito estabeleçam condições de maneira mais favorável ao obreiro em relação ao conteúdo normativo constitucional $\left(\mathrm{CF}\right.$, arts. $7 .^{\circ}$, caput e $\left.114, \$ 2 .^{\circ}\right)$. Destarte, há controvérsias doutrinária e jurisprudencial na adoção do critério que determina a norma mais favorável quando do cotejo entre normas jurídicas - componentes de distintos diplomas - que disciplinam de forma distinta uma mesma situação concreta. Os critérios de comparação esboçados na doutrina são: critério da acumulação ou fracionamento, critério do conglobamento e critério do conglobamento por instituiçôes. Entendemos que este último critério melhor atende aos auspícios da negociação coletiva, na medida em que torna mais objetivo a aferição da norma mais favorável.

\section{Referências}

BAYLOS, Antonio. La nueva posición de la negociación colectiva en la regulación de las relaciones de trabajo españolas. In: CONTEXTOS - Revista Crítica de Derecho Social, n. ${ }^{\circ}$ 1. Buenos Aires - Argentina:Editores del Puerto, 1997.

DELGADO, Maurício Godinho. Curso de Direito do Trabalho. São Paulo: LTr, 2002.

DEVEALI, Mario. El Derecho del Trabajo en su aplicación y sus tendencias, tomo I e II. Buenos Aires - Argentina: ASTREA, 1983. 
JEAMMAUD, Antoine. Cambios y futuro del derecho del trabajo en Francia. In: CONTEXTOS -Revista Crítica de Derecho Social, n. ${ }^{\circ}$ 1. Buenos Aires - Argentina: Editores del Puerto, 1997.

Libertad Sindical y Negociación Colectiva. Genebra: Oficina Internacional del Trabajo, 1994.

MANUS, Pedro Paulo Teixeira. Negociação Coletiva e Contrato Individual do Trabalho. São Paulo: Atlas, 2001.

ROBORTELLA, Luiz Carlos Amorim. Prevalência da Negociaçâo Coletiva sobre a Lei. In: O Direito do Trabalho na sociedade contemporânea. FREDIANI, Yone e TORRES DA SILVA, Jane Granzoto (Coords.). São Paulo: Editora Jurídica Brasileira, 2001. . O Moderno Direito do Trabalho. São Paulo: LTr, 1994.

RUPRECHT, Alfredo J. Relaçôes Coletivas de Trabalho. Tradução Edilson Alkmin Cunha - revisão técnica Irany Ferrari. São Paulo: LTr, 1995.

SILVA, José Afonso da. Curso de Direito Constitucional positivo. São Paulo: RT, 1998.

SIMON, Julio Cesar. Modelo Estatal y Negociación Colectiva. Buenos Aires - Argentina: La Ley, 1994.

. Negociacion Colectiva. Derecho Colectivo del Trabajo. Buenos Aires - Argentina: La Ley, 1998.

SÜSSEKIND, Arnaldo et al. Instituiçóes de Direito do Trabalho, vols. I e II. 20. ${ }^{\mathrm{a}} \mathrm{ed}$. atual. São Paulo: LTr, 2002.

URIARTE, Oscar Ermida. La Flexibilidad. Montevideo - Uruguay: Fundacion de Cultura Universitaria, 2001. . La negociación colectiva in pejus': algunas condicionantes teóricas. In: Revista Trabajo y Seguridad Social. Montevideo - Uruguay: Fundacion de Cultura Universitaria, 1994. 